\title{
Extracellular potassium and glutamate interact to modulate mitochondria in astrocytes
}

\author{
Theresa S. Rimmele $\#, 1$, Haissa de Castro Abrantes", Joel Wellbourne-Wood", Sylvain \\ Lengacher ${ }^{\S, 2}$, and Jean-Yves Chatton ${ }^{\# *}$ \\ "Department of Fundamental Neurosciences, University of Lausanne, 1005 Lausanne, \\ Switzerland, ${ }^{\S}$ Brain and Mind Institute, EPFL, 1015 Lausanne, Switzerland
}

*Corresponding author:

Jean-Yves Chatton, PhD

Dept. of Fundamental Neurosciences

University of Lausanne

Rue Bugnon 9

Ch-1005 Lausanne, Switzerland

Tel. +41-21-692-5106 Fax: +41-21-692-5105

E-mail: jean-yves.chatton@unil.ch

${ }^{1}$ Present address: F.M. Kirby Neurobiology Center, Boston Children's Hospital, Harvard Medical School, Boston, MA, 02115

${ }^{2}$ Present address: GliaPharm, 1202 Geneva, Switzerland

Running title: Glutamate, potassium and $\mathrm{pH}$ regulation of mitochondrial function

Key words: astrocytes, glutamate transport, $\mathrm{pH}$, mitochondria, extracellular potassium, mitochondrial potential, oxygen consumption rate, brain energy metabolism 


\section{FOR TABLE OF CONTENTS USE ONLY}

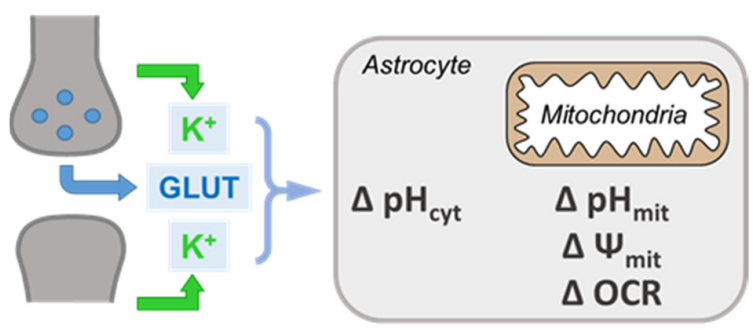

Extracellular potassium and glutamate interact to modulate mitochondria in astrocytes

by Theresa S. Rimmele, Haissa de Castro Abrantes, Joel Wellbourne-Wood, Sylvain Lengacher, and Jean-Yves Chatton 


\begin{abstract}
Astrocytes clear glutamate and potassium, both of which are released into the extracellular space during neuronal activity. These processes are intimately linked with energy metabolism. Whereas astrocyte glutamate uptake causes cytosolic and mitochondrial acidification, extracellular potassium induces bicarbonate-dependent cellular alkalinization. This study aimed at quantifying the combined impact of glutamate and extracellular potassium on mitochondrial parameters of primary cultured astrocytes. Glutamate in 3mM potassium caused a stronger acidification of mitochondria compared to cytosol. $15 \mathrm{mM}$ potassium caused alkalinization that was stronger in the cytosol than in mitochondria. While the combined application of $15 \mathrm{mM}$ potassium and glutamate led to a marked cytosolic alkalinization, $\mathrm{pH}$ only marginally increased in mitochondria. Thus, potassium and glutamate effects cannot be arithmetically summed, which also applies to their effects on mitochondrial potential and respiration. The data implies that, because of the non-linear interaction between the effects of potassium and glutamate, astrocytic energy metabolism will be differentially regulated.
\end{abstract}


One of the principal roles played by astrocytes in the brain is to assist neurons with their high energy demands. A number of studies performed both in vitro ${ }^{1-4}$ and in vivo ${ }^{5,6}$ have shown that during enhanced neuronal activity astrocytes engage their glycolytic metabolic pathway, which causes an increased glucose capture and utilization, and the subsequent release of lactate. This metabolic response, occurring in the presence of non-limiting oxygen is called aerobic glycolysis. The idea that astrocytes can favor aerobic glycolysis is puzzling, inasmuch as they possess a substantial density of mitochondria that enable them to produce ATP with a seventeen-fold higher yield. The higher glycolytic nature of astrocytes compared to neurons may be due to different expression levels of mitochondrial respiratory chain enzymes ${ }^{7}$. Mitochondria have been shown to regulate their internal ionic composition as the result of changes in cytosolic ion concentrations, which may adapt their metabolism to cellular energy demands. In previous studies our lab showed ${ }^{8}$ that rapid mitochondrial transients involving a localized ATP microdomain trigger a $\mathrm{Na}^{+}$-mediated mitochondrial depolarization in primary cultured mouse cortical astrocytes, which transiently enhances the activity of the mitochondrial respiratory chain. Glutamate transporters exhibit a complex stoichiometry with three $\mathrm{Na}^{+}$and one $\mathrm{H}^{+}$entering with glutamate in exchange for one $\mathrm{K}^{+9}$. Thus, glutamate uptake is coupled to the cellular entry of $\mathrm{H}^{+}$and $\mathrm{Na}^{+}$, and is known to causes cytosolic acidification, observed both in cultured astrocytes ${ }^{10}$ and hippocampal slices ${ }^{11}$. According to the chemiosmotic coupling hypothesis, the mitochondrial matrix is expected to be more alkaline than the cytosol, because of the anticipated low permeability of the mitochondrial inner membrane and the constant extrusion of protons across mitochondrial inner membrane to cations by the mitochondrial respiratory chain ${ }^{12}$. However, the observed glutamate transport-induced cytosolic acidification was found to spread to mitochondria, resulting in a large $\mathrm{pH}$ drop in this compartment ${ }^{13}$. The acidification resulted in the collapse of the cytosolto-mitochondrial matrix $\mathrm{pH}$ gradient.

On the other hand, during neuronal activity, the repolarization phase of firing neurons leads to the release and diffusion of $\mathrm{K}^{+}$into the extracellular space ${ }^{14}$. Astrocytes provide highly efficient mechanisms for rapid $\mathrm{K}^{+}$uptake and redistribution in the brain ${ }^{15}$. They express both active and passive mechanisms for $\mathrm{K}^{+}$uptake and release, such as the inwardly rectifying potassium channel $4.1\left(\mathrm{~K}_{\mathrm{ir}} 4.1\right)^{16,17}$, the $\mathrm{Na}^{+} / \mathrm{K}^{+} / \mathrm{Cl}^{-}$cotransporter, and the $\mathrm{Na}^{+} / \mathrm{K}^{+}$ATPase ${ }^{18,19}$. 
Astrocytes are extensively interconnected by gap junctions, forming a cellular syncytium, and are capable of redistributing $\mathrm{K}^{+}$to distant sites $^{17}$.

Elevated extracellular $\mathrm{K}^{+}$concentrations $\left(\left[\mathrm{K}^{+}\right]_{0}\right)$ mildly depolarize the surrounding astrocyte plasma membrane, which can cause the reversal of the $\mathrm{Na}^{+} /$bicarbonate exchanger (NBCe1) activity $^{20}$. Thus, in bicarbonate-containing media, this effect results in an influx of bicarbonate into the cell leading to cytosolic alkalinization ${ }^{21}$. This mechanism was shown to enhance (cytosolic) glycolysis immediately and reversibly, via stimulation of the phosphofructokinase ${ }^{22}$.

The aim of the present study was to investigate how glutamate and elevated $\left[\mathrm{K}^{+}\right]_{\mathrm{o}}$ individually and simultaneously applied, impact metabolic responses of primary cultured astrocytes. We therefore studied cytosolic and mitochondrial $\mathrm{pH}$, mitochondrial electrical potential $\left(\Delta \Psi_{\text {mit }}\right)$, and cellular oxygen consumption rate (OCR) in physiological $\mathrm{CO}_{2} /$ bicarbonate-buffered solutions, and investigated the influence of glutamate transport and elevated $\left[\mathrm{K}^{+}\right]_{\mathrm{o}}$ in order to reach a better understanding of astrocyte energy metabolism regulation. 


\section{RESULTS AND DISCUSSION}

We designed experiments to evaluate the respective impact of extracellular glutamate and $\mathrm{K}^{+}$, both known to fluctuate during network activity, on astrocyte cytosolic and mitochondrial $\mathrm{pH}$ under physiological conditions. To create conditions relevant to the in vivo setting, all experiments were performed in $\mathrm{CO}_{2} /$ bicarbonate-buffered solutions. To investigate cytosolic $\mathrm{pH}$ changes, 2-3-week-old primary mouse cortical astrocytes were loaded with the $\mathrm{pH}$ sensitive fluorescent dye BCECF. BCECF-loaded cells (Fig. 1, a1) displayed intense fluorescence throughout their cytoplasm with typical bright nuclei ${ }^{23}{ }^{24}$. In comparison, astrocytes transfected with the MitoSypHer plasmid exhibited a fluorescent protein expression pattern typical of mitochondrial labeling ${ }^{25}$, with dark nuclei and punctate staining of rod-like structures 2-3 days after transfection (Fig. 1, a2). In both compartments we found a stable baseline of $\mathrm{pH}$ under resting conditions, which was on average $7.37 \pm 0.04$ in the cytosol and $7.25 \pm 0.07$ in mitochondria.

Glutamate transport by astrocytes was shown to cause a cytosolic $\mathrm{pH}$ decrease as a result of the proton co-transported with glutamate ${ }^{10,11,13}$. We first examined the effects of glutamate transport on cytosolic and mitochondrial $\mathrm{pH}$, respectively, in physiological $\mathrm{CO}_{2} /$ bicarbonate-buffered solutions by applying glutamate $(200 \mu \mathrm{M})$ in low $(3 \mathrm{mM}) \mathrm{K}^{+}$ containing solutions. In these and following experiments, the application of glutamate (or $\mathrm{K}^{+}$, see below) was maintained until a stable response (plateau) was achieved before returning to the control solution. The time of application therefore somewhat varied according the cells' responses in individual experiments. The application of glutamate caused cytosolic acidification $(-0.07 \pm 0.003 \mathrm{pH}$ units) as depicted in Fig. 1, b1. Glutamate-induced mitochondrial acidification was found to be stronger (Fig. 1, b2) $(-0.18 \pm 0.03 \mathrm{pH}$ units). A possible explanation for this effect could be a lower $\mathrm{H}^{+}$buffering capacity of mitochondria in comparison to the cytosol, as was proposed before ${ }^{25}$. Another factor could be facilitated uptake of $\mathrm{H}^{+}$into mitochondria. $\mathrm{H}^{+}$can potentially enter this subcellular compartment via several mechanisms, including mitochondrial uncoupling proteins ${ }^{26}$ or cation-proton exchangers (e.g. $\mathrm{Na}^{+} / \mathrm{H}^{+}$exchanger or $\mathrm{K}^{+} / \mathrm{H}^{+}$exchanger) ${ }^{27}$. Overall, these results indicate that glutamate transporter activity causes cellular acidification in physiological $\mathrm{CO}_{2} /$ bicarbonate buffered salines, and that this acidification is transmitted to mitochondria, similar to what was described before in HEPES-buffered solutions ${ }^{13}$. 
a1

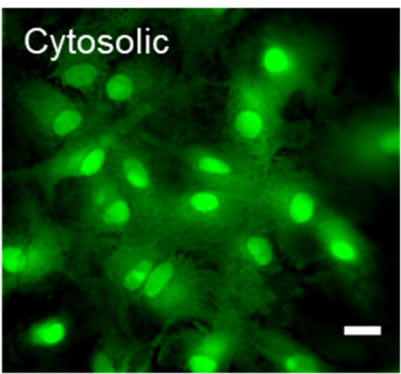

b1

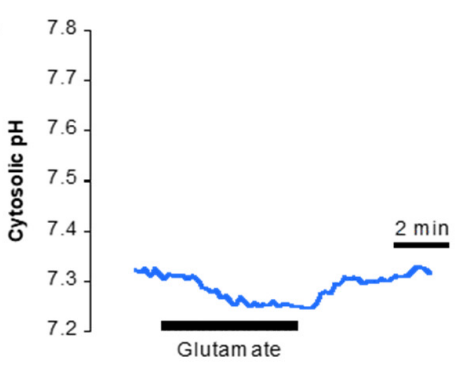

c1

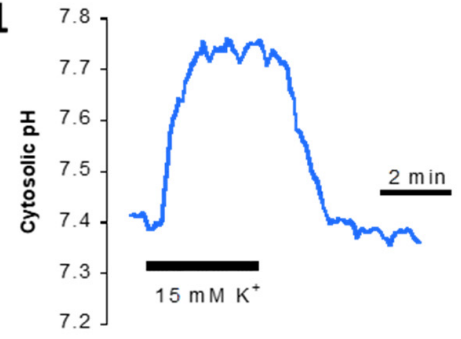

d1

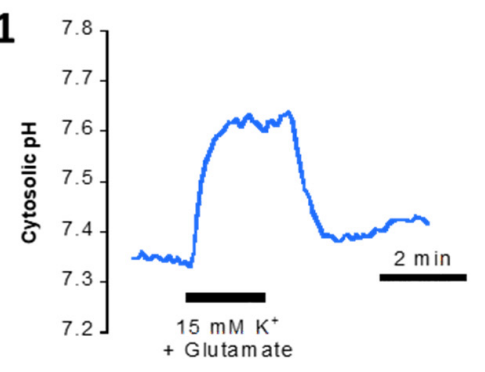

a2

\section{Mitochondrial}

b2

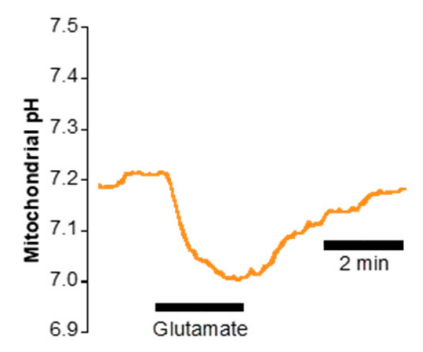

c2

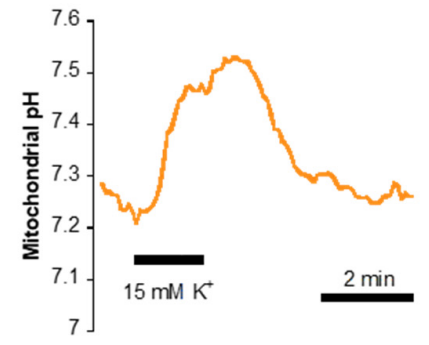

d2

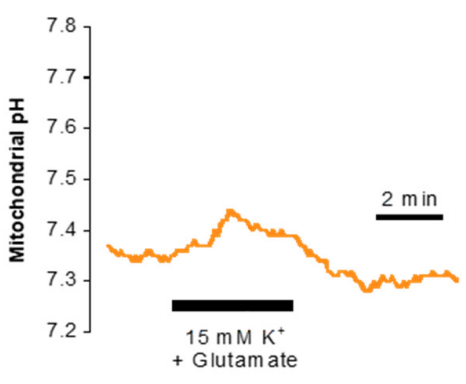

Mitochondria

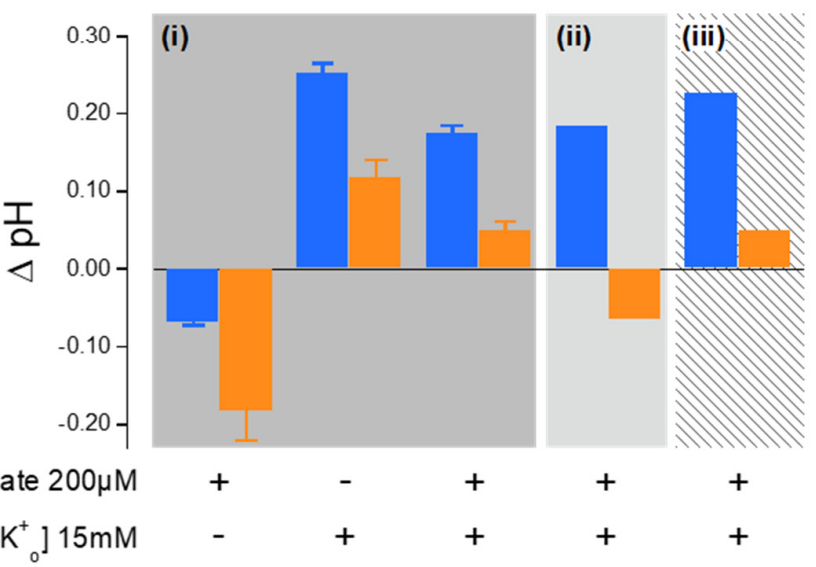


Figure 1. Respective effects of glutamate and $\left[\mathrm{K}^{+}\right]_{\mathrm{o}}$ on intracellular $\mathrm{pH}$. Cytosolic (left panels) and mitochondrial (right panels) $\mathrm{pH}$ in astrocytes were monitored using the fluorescent indicator BCECF (a1) and the genetically encoded MitoSypHer fluorescent protein targeted to the mitochondrial matrix (a2). Scale bars, $20 \mu \mathrm{m}$. The effects of $200 \mu \mathrm{M}$ glutamate and $15 \mathrm{mM}$ $\mathrm{K}^{+}$applied separately or in combination in bicarbonate-containing solutions are compared. Example traces of effects of glutamate application are shown for cytosolic $\mathrm{pH}$ (b1, $\mathrm{n}=32$ cells, 4 exp) and mitochondrial $\mathrm{pH}$ (b2: $\mathrm{n}=9$ cells, 8 exp), as well as the $15 \mathrm{mM} \mathrm{K}^{+}$effect on these parameters ( $\mathbf{c} 1: \mathrm{n}=33$ cells, 4 exp; $\mathbf{c 2}: \mathrm{n}=12$ cells, 7 exp). Combined effects of high $\mathrm{K}^{+}$and glutamate on cytosolic $\mathrm{pH}$ (d1: $\mathrm{n}=33$ cells, 4 exp) and mitochondrial $\mathrm{pH}$ (d2: $\mathrm{n}=12$ cells, 7 exp) are shown. (e) Quantitative effects of glutamate and $\left[\mathrm{K}^{+}\right]_{\text {o }}$ on cytosolic and mitochondrial $\mathrm{pH}$. (i) Mean amplitudes of $\mathrm{pH}$ changes $( \pm \mathrm{SEM}$ ) were compiled from experiments presented above. (ii) Raw projection of the expected $\mathrm{pH}$ changes in cytosol and mitochondria resulting from the arithmetic summation of acidification/alkalinization individually caused by $200 \mu \mathrm{M}$ glutamate and $15 \mathrm{mM}\left[\mathrm{K}^{+}\right]_{\mathrm{o}}$. (iii) Projection taking into account the inhibitory action of elevated $\left[\mathrm{K}^{+}\right]_{0}$ on glutamate glial transport activity, as previously described ${ }^{34}$.

A cellular alkalinizing effect of elevated $\left[\mathrm{K}^{+}\right]_{\text {o }}$ on astrocytes was described before ${ }^{28-31}$. We then investigated the effect of high $\left[\mathrm{K}^{+}\right]_{\mathrm{o}}$. We chose to apply a $\left[\mathrm{K}^{+}\right]_{\mathrm{o}}$ of $15 \mathrm{mM}$, close to the previously described $\left[\mathrm{K}^{+}\right]_{0}$ ceiling level ${ }^{32}$, as the highest concentration expected to be found in the brain. This concentration allows us to compare results to those of previous studies ${ }^{20,22}$. We observed a rapid and marked alkalinization of the cytosol $\left(0.25 \pm 0.01 \mathrm{pH}\right.$ units) when $\left[\mathrm{K}^{+}\right]_{\mathrm{o}}$ was switched from 3 to $15 \mathrm{mM}$ (Fig. 1, c1), which is consistent with a response involving the NBCe1 activity as described other studies ${ }^{20,21}$. Alkalinization was not observed in bicarbonatefree HEPES-buffered solutions (not shown). The alkalinization caused by the $\left[\mathrm{K}^{+}\right]_{\mathrm{o}}$ switch was found to occur in mitochondria as well, with an amplitude of $0.12 \pm 0.02 \mathrm{pH}$ units (Fig. 1, c2). Thus, the effect of $\left[\mathrm{K}^{+}\right]_{\mathrm{o}}$ on $\mathrm{pH}$ was found to be stronger in the cytosol in comparison to mitochondria. $\mathrm{pH}$ in both compartments returned rapidly to their resting level after switching back to baseline $\left[\mathrm{K}^{+}\right]_{0}$. Among possible mechanisms underlying the mitochondrial alkalinization is the $\mathrm{K}^{+}$transport to mitochondrial matrix performed by the $\mathrm{H}^{+} / \mathrm{K}^{+}$exchanger ${ }^{33}$.

In vivo, neuronal glutamate release and $\mathrm{K}^{+}$extrusion into the extracellular space are two processes expected to overlap in time and space. We therefore combined the application of $15 \mathrm{mM} \mathrm{K}^{+}$and $200 \mu \mathrm{M}$ glutamate in the next experiments. The addition of glutamate and high $\mathrm{K}^{+}$resulted in a net alkalinization of cytosol $(0.18 \pm 0.009 \mathrm{pH}$ units) (Fig. 1, d1). Interestingly, we found mitochondrial $\mathrm{pH}$ to undergo only slight alkalinization $(0.05 \pm 0.01 \mathrm{pH}$ units) (Fig. 1, d2). 
The quantitative $\mathrm{pH}$ effects of glutamate and high $\mathrm{K}^{+}$on astrocytes in bicarbonatecontaining solutions are summarized in Fig. 1e, panel i). The figure displays the acidifying

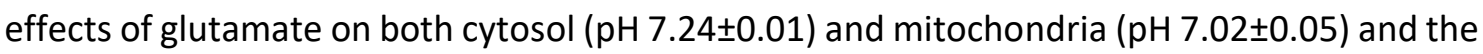
alkalinization caused by high $\left[\mathrm{K}^{+}\right]_{0}$ in the two compartments (cytosol pH 7.68 \pm 0.01 ),

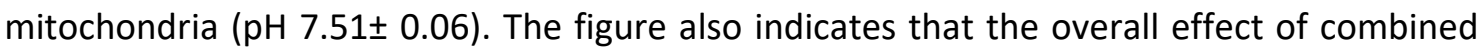
application of glutamate and $\mathrm{K}^{+}$on $\mathrm{pH}$ was a strong cytosolic alkalinization $(\mathrm{pH} 7.53 \pm 0.03)$, whereas mitochondria were only marginally alkalinized ( $\mathrm{pH} 7.20 \pm 0.03$ ). In this condition, their combined effect on cytosolic $\mathrm{pH}$ was relatively similar, although lower, to the value estimated from the summation of the effect of glutamate and $15 \mathrm{mM} \mathrm{K}^{+}$individually (Fig. 1e, panel ii). It can be seen, however, that the $\mathrm{pH}$ change in mitochondria did not match the arithmetic projection of the effects in isolation (Fig. 1e, panel iii), meaning the acidifying and alkalinizing effects of glutamate and high $\left[\mathrm{K}^{+}\right]_{\mathrm{o}}$ respectively did not add up in a linear manner.

This observation indicates that glutamate and high $\left[\mathrm{K}^{+}\right]_{0}$ do not behave as independent variables, but somehow influence each other. Indeed, we recently demonstrated that $\left[\mathrm{K}^{+}\right]_{\mathrm{o}}$ exerts tight control over the kinetics of the glutamate transporter, in which increasing $\left[\mathrm{K}^{+}\right]_{\mathrm{o}}$ over the physiological range has an immediate and reversible inhibitory action on glutamate transporters ${ }^{34}$. To verify whether this interaction at the level of glutamate transporters could provide an explanation for this unanticipated results on mitochondrial $\mathrm{pH}$, we considered the fact that the glutamate transport activity in $15 \mathrm{mM}\left[\mathrm{K}^{+}\right]_{\mathrm{o}}$ is actually reduced to $37 \%$ of its activity in $3 \mathrm{mM}\left[\mathrm{K}^{+}\right]_{0}{ }^{34}$. We postulated that the amplitude of the actual glutamate-mediated acidification in these high $\left[\mathrm{K}^{+}\right]_{0}$ conditions is correspondingly lower. Fig. 1e (panel iii) shows that the calculated summation of glutamate- and $\left[\mathrm{K}^{+}\right]_{0}$-mediated effects on $\mathrm{pH}$ becomes very close to the values observed experimentally (Fig. 1e, panel i) when the inhibitory effect of elevated $\left[\mathrm{K}^{+}\right]_{\mathrm{o}}$ on glutamate transport is taken into account.

$\left[\mathrm{K}^{+}\right]_{\text {。 }}$ elevations have been shown to moderately depolarize the astrocyte plasma membrane, and because it is taken up by astrocytes, cytosolic $\mathrm{K}^{+}$in turn also transiently increases ${ }^{24}$. On the other hand, astrocyte glutamate transporters (GLAST and GLT-1) operate with a complex stoichiometry of three $\mathrm{Na}^{+}$and one $\mathrm{H}^{+}$entering with glutamate in exchange for one $\mathrm{K}^{+9}$. Thus, this counter-transport of $\mathrm{K}^{+}$was shown to cause measurable cytosolic $\mathrm{K}^{+}$ decreases ${ }^{24}$. As cytosolic $\mathrm{K}^{+}$fluctuations could impact $\Delta \Psi_{\text {mit }}$ and their ability to produce ATP, we investigated their respective impact on the mitochondrial potential, which is estimated to 
be around $-180 \mathrm{mV}$ under resting conditions. Glutamate transport was found to mildly hyperpolarize $\Delta \Psi_{\text {mit, }}$ whereas uncoupling agents, for instance carbonyl cyanide-4(trifluoromethoxy)phenylhydrazone (FCCP), rapidly depolarize mitochondria and abolish $\Delta \Psi_{\mathrm{mit}}{ }^{35}$.

To assess the impact of $\left[\mathrm{K}^{+}\right]_{\mathrm{o}}$ alone and in combination with glutamate on $\Delta \Psi_{\text {mit, }}$, we used the mitochondrial potential fluorescent indicator Rhodamine 123 (Rh123). We found that application of glutamate led to a slight decrease in Rh123 fluorescence (Fig. 2a,b), which corresponds to a hyperpolarization of $\Delta \Psi_{\text {mit. }}$. Conversely, superfusion with $15 \mathrm{mM} \mathrm{K}^{+}$led to substantial increase in Rh123 fluorescence, i.e. depolarization of $\Delta \Psi_{\text {mit }}$. The figure shows that the combined application of glutamate and $15 \mathrm{mM}\left[\mathrm{K}^{+}\right]_{\mathrm{o}}$ caused a depolarization of $\Delta \Psi_{\text {mit, }}$, however less efficiently than $15 \mathrm{mM} \mathrm{K}^{+}$alone. $\Delta \Psi_{\text {mit }}$ responses between conditions overall followed the same pattern in HEPES-buffered solutions and in bicarbonate solutions (Fig. 3c). There was however a statistical difference between HEPES and bicarbonate conditions for the $\Delta \Psi_{\text {mit }}$ response to $15 \mathrm{mM} \mathrm{K}^{+}$application $(\mathrm{p}=0.04)$ and the one to $15 \mathrm{mM} \mathrm{K}^{+}$plus glutamate $(p<0.001)$. This suggests that $\mathrm{pH}$ changes may influence part of the observed effects of glutamate and $\left[\mathrm{K}^{+}\right]_{\mathrm{o}}$ on $\Delta \Psi_{\text {mit. }}$ Thus, the effect of glutamate on $\Delta \Psi_{\text {mit }}$ was markedly different depending on the $\left[\mathrm{K}^{+}\right]_{0}$ concentration, which highlights the complex and non-linear relationship between the two extracellular species. 

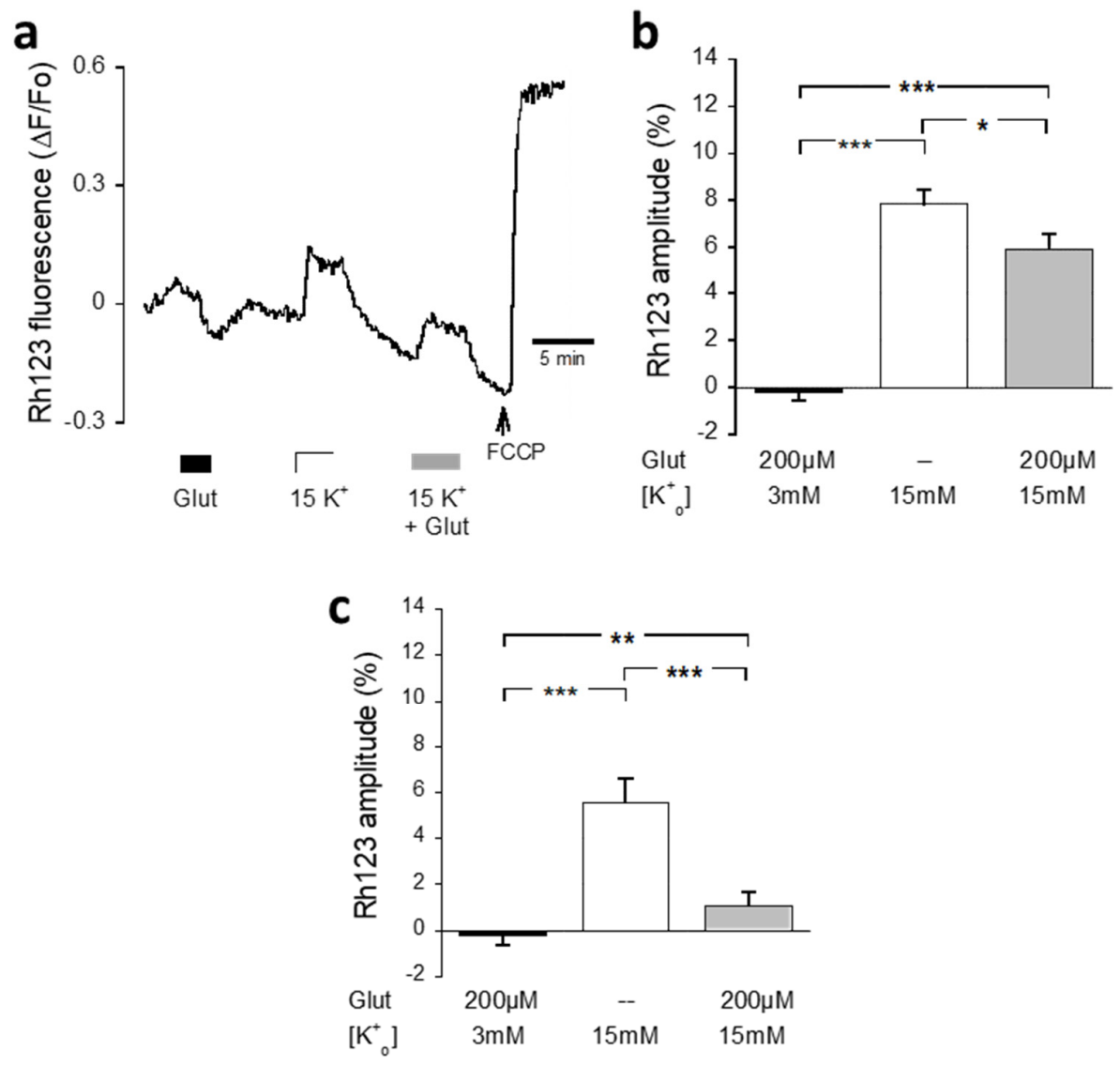

Figure 2. Respective effects of glutamate and $\left[\mathrm{K}^{+}\right]_{0}$ on mitochondrial electrical potential $\left(\Delta \Psi_{\text {mit }}\right)$ in astrocytes monitored using the fluorescent indicator Rhod123. The effects of glutamate and $15 \mathrm{mM}\left[\mathrm{K}^{+}\right]_{0}$ applied separately or in combination in bicarbonate-containing solutions are compared. Representative trace $(a)$ in arbitrary fluorescence units $\left(\Delta F / F_{0}\right)$ of intensity change of Rhod 123 fluorescence in cells superfused with $200 \mu \mathrm{M}$ glutamate, $15 \mathrm{mM}$ $\mathrm{K}^{+}$and their combined application ( $\mathrm{n}=195$ cells, 19 exp). (b) The effects of glutamate application are shown for Rh123 amplitude (black column) as well as the $15 \mathrm{mM} \mathrm{K}^{+}$effect on this parameter (white column) and combined effects of high $\mathrm{K}^{+}$and glutamate (grey column) as percentage of FCCP response (data are means \pm SEM from 19 exp). (c) The effects of glutamate application in the absence of $\mathrm{CO}_{2}$ /bicarbonate are shown for Rh123 amplitude (black column) in HEPES-buffered salines, as well as the $15 \mathrm{mM}\left[\mathrm{K}^{+}\right]_{0}$ effect on this parameter (white column) and combined effects of high $\mathrm{K}^{+}$and glutamate (grey column) as percentage of FCCP response (data are means \pm SEM from 14 exp).

In the next phase we tested if the increased $\left[\mathrm{K}^{+}\right]_{\mathrm{o}}$ and concurrent $\left[\mathrm{K}^{+}\right]_{\mathrm{o}}$ and glutamate application impacted the OCR in bicarbonate-containing solutions. Because the instrument used in this study measures OCR at ambient $\mathrm{CO}_{2}$ tension only, we performed experiments in solutions containing $1 \mathrm{mM}$ bicarbonate in the presence of $10 \mathrm{mM}$ HEPES, which allowed $\mathrm{pH}$ to 
remain stable even in the absence of added $\mathrm{CO}_{2}$. Fig. S1 shows that in the presence of $1 \mathrm{mM}$

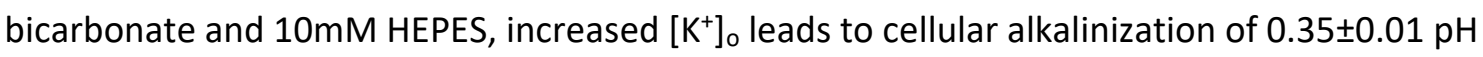
units ( $n=52$ cells, 5 exp).
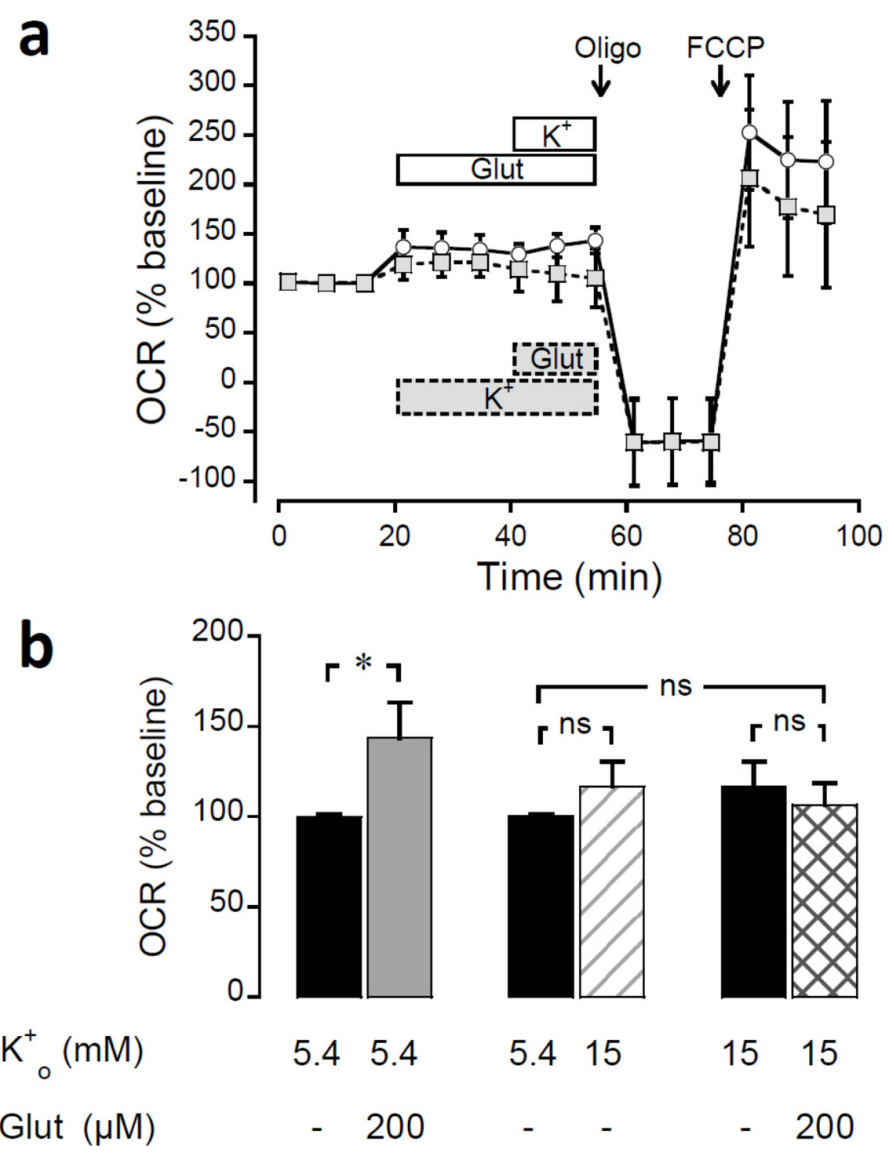

Figure 3. Effects of glutamate and increased $\left[\mathrm{K}^{+}\right]_{\mathrm{o}}$ on the oxygen consumption rate (OCR) of cultured astrocytes measured using an extracellular flux analyzer. Measurements were performed in base medium which contains a standard $5.4 \mathrm{mM} \mathrm{K}^{+}$concentration. (a) Time course of OCR adjusted to baseline with sequential application of either $\mathrm{K}^{+}(15 \mathrm{mM})$ and then glutamate $(200 \mu \mathrm{M})$ (grey squares, dotted line), or vice-versa (white circles, plain line). Oligomycin $(1 \mu \mathrm{M})$ and FCCP $(2 \mu \mathrm{M})$ were then applied as controls to inhibit and maximize mitochondrial respiration, respectively. (b) Quantification of the effect of glutamate and/or $\mathrm{K}^{+}$on OCR. (All data are means $\pm \mathrm{SEM}, \mathrm{n}=16$ samples, 8 exp). 
In a series of experiments using bicarbonate-containing solutions, glutamate application

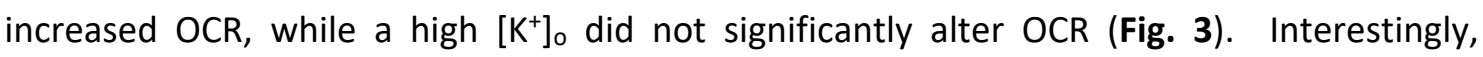
glutamate application in the presence of high $\left[\mathrm{K}^{+}\right]_{\mathrm{o}}$ no longer had an effect on OCR. The cancellation of glutamate's effect on OCR by $\left[\mathrm{K}^{+}\right]_{\mathrm{o}}$ is another illustration of the non-additive effects of the two extracellular species which further highlights the interactive nature of their effects on mitochondrial parameters.

In conclusion, we confirmed in this study that a rise of $\left[\mathrm{K}^{+}\right]_{\mathrm{o}}$ causes astrocytic cellular alkalinization, which is knowns to be mediated by the bicarbonate exchanger $\mathrm{NBCe}{ }^{20,22}$ and leads to stimulation of glycolysis ${ }^{20}$. Conversely, we also found, as others ${ }^{10,11}$, that glutamate transport leads to cytosolic acidification in astrocytes, which spreads to their mitochondria ${ }^{13}$. In the absence of bicarbonate, the stronger mitochondrial acidification evoked by glutamate was found to abolish the cytosol-to-mitochondrial matrix $\mathrm{pH}$ gradient ${ }^{13}$. In the present study, we show that in bicarbonate-buffered solutions, i.e. a more physiological situation, we could demonstrate that glutamate transport also leads to a stronger acidification of mitochondria compared to the cytosol. Conversely, in these conditions, elevated $\left[K^{+}\right]_{\circ}$ led to a more pronounced alkalinization of the cytosol compared to mitochondria. The effects of glutamate and elevated $\left[\mathrm{K}^{+}\right]_{\mathrm{o}}$ were also determined to interact in a non-linear manner, in the sense that their combined effect was not equal to their cumulative individual effects. We found that the same interaction between $\left[\mathrm{K}^{+}\right]_{\circ}$ and glutamate also affects $\Delta \Psi_{\text {mit }}$ and OCR. Future investigations should aim to clarify if there is a causal relationship between these parameters. Overall, we conclude that, depending on the timing and amplitudes of $\left[\mathrm{K}^{+}\right]_{\mathrm{o}}$ and extracellular glutamate fluctuations, cellular and mitochondrial physiology are likely to be differentially modulated. 


\section{METHODS}

Cell culture- Cortical astrocytes in primary culture were prepared from 1- to 3-day-old C57BI6 mice as previously described ${ }^{36}$. Astrocytes were cultured for 3-4 weeks in DME medium (Sigma) plus 10\% FCS before experiments and plated on glass coverslips for imaging. All experimental procedures were carried out in strict accordance with the recommendations of the Swiss Ordinance on Animal Experimentation and were specifically approved for this study by the cantonal veterinary office (authorization \#VD1288).

Fluorescence imaging and astrocyte transfection - Low-light level fluorescence imaging was performed on an inverted epifluorescence microscope (Axiovert 100M, Carl Zeiss) using a 40X 1.3 N.A. oil-immersion objective lens. Fluorescence excitation wavelengths were selected using a monochromator (Till Photonics, Planegg, Germany) and fluorescence was detected using a 12-bit cooled CCD camera (Princeton Instruments) or EM-CCD camera (Andor). Image acquisition was computer-controlled using Metafluor software (Universal Imaging, Reading, PA). Dye-loaded cells were placed in a thermostated chamber designed for rapid exchange of perfusion solutions $s^{37}$ and superfused at $35^{\circ} \mathrm{C}$.

The experimental solutions contained $(\mathrm{mM}) \mathrm{NaCl}, 137.4 ; \mathrm{KCl}, 3 ; \mathrm{NaHCO}_{3}, 25 ; \mathrm{CaCl}_{2}, 1.3$; $\mathrm{MgSO}_{4}, 0.8$; and $\mathrm{NaH}_{2} \mathrm{PO}_{4}, 0.78$, glucose, 5, and were bubbled with $5 \% \mathrm{CO}_{2} / 95 \%$ air. $\mathrm{pH}$ stability in the experimental solutions was ensured by minimizing $\mathrm{CO}_{2}$ fluctuations. Bicarbonate-free HEPES-solutions contained (mM) $\mathrm{NaCl}, 162.6 ; \mathrm{KCl}, 3 ; \mathrm{HEPES}, 20 ; \mathrm{CaCl}_{2}, 1.3$; $\mathrm{MgSO}_{4}, 0.8 ; \mathrm{NaH}_{2} \mathrm{PO}_{4}, 0.78 ;$ glucose, 5 . When using different $\mathrm{K}^{+}$concentrations, $\mathrm{NaCl}$ was accordingly adjusted to maintain isotonicity. Solutions for dye loading contained (mM) $\mathrm{NaCl}$, 160; $\mathrm{KCl}$, 5.4; HEPES, 20; $\mathrm{CaCl}_{2}, 1.3 ; \mathrm{MgSO}_{4}, 0.8 ; \mathrm{NaH}_{2} \mathrm{PO}_{4}, 0.78$; glucose, 20 and were supplemented with $0.1 \%$ Pluronic F-127 (Molecular Probes, Eugene, OR). In experiments involving more than one solution application, the order was alternated between experiments to exclude order-related effects.

For cytosolic $\mathrm{pH}$ measurement, astrocytes were loaded at $37^{\circ} \mathrm{C}$ for $10 \mathrm{~min}$ with the $\mathrm{pH}$ sensitive dye 2-bis(carboxyethyl)-5,6-carboxyfluorescein (BCECF)-AM (Teflabs, Austin, USA). Cytosolic pH was measured by fluorescence microscopy as previously described. Briefly, cells were placed in a thermostatted chamber designed for rapid exchange of perfusion solutions and superfused at $35^{\circ} \mathrm{C}$. BCECF fluorescence was sequentially excited at 490 and $440 \mathrm{~nm}$ and 
detected at $>535 \mathrm{~nm}$. For in situ calibration of cytosolic $\mathrm{pH}$, cells were permeabilized using $10 \mu \mathrm{g} / \mathrm{ml}$ nigericin ${ }^{38}$. Cells were then sequentially perfused with solutions buffered at $\mathrm{pH} 6.5,7$, 7.5, 8 and containing $(\mathrm{mM}) \mathrm{NaCl}, 20 ; \mathrm{KCl}, 120$; Hepes, $10 ; \mathrm{CaCl}_{2}, 1.3 ; \mathrm{MgSO}_{4}, 0.8$; and $\mathrm{NaH}_{2} \mathrm{PO}_{4}$, 0.78 .

For mitochondrial matrix $\mathrm{pH}$ measurement, we used the genetically encoded $\mathrm{pH}$ indicator MitoSypHer ${ }^{13}$, 25 . Two-week-old astrocytes were placed in $2 \mathrm{ml}$ of antibiotic-free and serumfree DMEM with Lipofectamin 2000 (Invitrogen) and DNA encoding for genetically encoded $\mathrm{pH}$ indicator MitoSypHer. Quantities of DNA/Lipofectamin were $3 \mu \mathrm{g}$ of DNA/6 $\mu \mathrm{l}$ of Lipofectamin for MitoSypHer. After 4h, the medium was changed with DMEM plus $10 \%$ serum, and the cells were used 2-3 days after transfection. Mitochondrial $\mathrm{pH}$ was measured by fluorescence microscopy as described above for BCECF measurements. MitoSypHer fluorescence was sequentially excited at 490 and $420 \mathrm{~nm}$ and detected at $>515 \mathrm{~nm}$. At the end of each experiment, in situ calibration was performed by permeabilization of cells with $10 \mu \mathrm{m}$ monensin and $3 \mu \mathrm{m}$ gramicidin and superfused with a series of calibration solutions of given $\mathrm{pH}$ values (pH 5.9, 7.0 7.5, and 8.0). Calibration solutions contained (in $\mathrm{mM}$ ): $\mathrm{NaCl}, 20 ; \mathrm{KCl}$, 120; $\mathrm{MgCl}_{2}, 0.5 ;$ EGTA, 0.2; HEPES, 20.

For mitochondrial potential measurements, we used the cationic fluorescent dye Rh123 in quench mode, as previously described ${ }^{39}, 40$. Cultured astrocytes were incubated with $26 \mu \mathrm{M}$ Rh123 for 20min at room temperature. Rh123 fluorescence was excited at $490 \mathrm{~nm}$ and detected at $>520 \mathrm{~nm}$. At the end of each experiment, the mitochondrial uncoupler carbonyl cyanide 4-(trifluoro-methoxy)phenylhydrazone (FCCP) was applied to depolarize mitochondria and verify the responsiveness of the dye.

Oxygen consumption rate- Assessment of OCR was performed using a non-invasive Extracellular Flux Analyzer (Seahorse XFp, Agilent, Bucher Biotec, Basel, Switzerland), composed of calibrated optical sensors which directly measure the oxygen consumption rate in a $2 \mu \mathrm{l}$ microchamber with limited diffusion. The depletion of oxygen in the medium is measured several times during a defined period. Up to four drug or compound additions can be delivered during the experiment at defined time points. Cells were plated at a density of 30,000 cells/well in XFp cell culture miniplates having growth surface area of $0.106 \mathrm{~cm}^{2} /$ well (XFp FluxPak, Bucher Biotec), and used 2-to-3 weeks after plating. The medium was composed of base medium (Seahorse XF Base Medium, Bucher Biotec) based on the DME medium 
formulation that contains $5.4 \mathrm{mM} \mathrm{K}^{+}$. The medium was supplemented with $10 \mathrm{mM}$ glucose, $5 \mathrm{mM}$ pyruvate, and $1 \mathrm{mM} \mathrm{NaHCO}_{3}$. For measurements, glutamate and $\mathrm{KCl}$ were injected in sequences in order to reach extracellular concentrations of $200 \mu \mathrm{M}$ glutamate and $15 \mathrm{mM} \mathrm{K}^{+}$. In all experiments, subsequent injections of $1 \mu \mathrm{M}$ oligomycin and $2 \mu \mathrm{M}$ FCCP (Seahorse XFp Cell Mito Stress Test Kit) were used as controls to inhibit and maximize mitochondrial respiration, respectively. Effects of added compounds were normalized to the basal OCR. Results are expressed as percentage of control values.

Data Analysis and statistics - Fluorescence intensity traces were drawn from regions of interest selected in up to 10 individual cells from the field of view. Further calculations were done with Excel (Microsoft). Graphs and curve fitting were done with Kaleidagraph (Synergy Software). Unless otherwise indicated, a paired Student's t-test was performed for each experiment group to assess the statistical significance against respective controls, $*, * *$, and $* * *$ refer to $p$ values of $0.05,0.01$, and 0.001 , respectively.

Drugs - Nigericin was from Abcam (Cambidge, UK). Rh123 was from Molecular Probes (ThermoFisher Scientific). BCECF-AM was from Teflabs (Austin TX). All other chemicals were from Sigma-Aldrich (Buchs, Switzerland).

\section{ACKNOWLEDGMENTS}

This work was supported by grant \#31003A-135720 from the Swiss National Science Foundation to J-Y Chatton.

\section{AUTHOR CONTRIBUTIONS}

T.S.R. and J.Y.C. designed the project; T.S.R., H.C.A., J.W.W., S.L. and J.Y.C performed and analyzed the experiments, and produced the figures; T.S.R, J.Y.C. wrote the manuscript. Funding acquisition: J.Y.C.

\section{CONFLICT OF INTEREST}

The authors declare no conflicts of interest. 


\section{ABBREVIATIONS}

Rh123, rhodamine 123; BCECF AM, 2-bis(carboxyethyl)-5,6-carboxyfluorescein acetoxymethyl ester; $\left[\mathrm{K}^{+}\right]_{0}$, extracellular $\mathrm{K}^{+}$concentration;

\section{SUPPORTING INFORMATION}

Figure S1. Example trace of intracellular $\mathrm{pH}$ measured in astrocytes bathed in solutions containing $1 \mathrm{mM}$ bicarbonate and buffered using $10 \mathrm{mM}$ HEPES at ambient $\mathrm{CO}_{2}$ levels. 


\section{REFERENCES}

1. Pellerin, L., and Magistretti, P. J. (1994) Glutamate uptake into astrocytes stimulates aerobic glycolysis: a mechanism coupling neuronal activity to glucose utilization. Proc. Natl. Acad. Sci. USA 91, 10625-10629.

2. Schurr, A., Payne, R. S., Miller, J. J., and Rigor, B. M. (1997) Brain lactate, not glucose, fuels the recovery of synaptic function from hypoxia upon reoxygenation: an in vitro study. Brain Res. 744, 105-111.

3. Schurr, A., Payne, R. S., Miller, J. J., and Rigor, B. M. (1997) Brain lactate is an obligatory aerobic energy substrate for functional recovery after hypoxia: further in vitro validation. J. Neurochem. $69,423-426$.

4. Schurr, A., Payne, R. S., Miller, J. J., and Rigor, B. M. (1997) Glia are the main source of lactate utilized by neurons for recovery of function posthypoxia. Brain Res. 774, 221-224.

5. Cassady, C. J., Phillis, J. W., and O'Regan, M. H. (2001) Further studies on the effects of topical lactate on amino acid efflux from the ischemic rat cortex. Brain Res. 901, 30-37.

6. Schurr, A., Payne, R. S., Miller, J. J., Tseng, M. T., and Rigor, B. M. (2001) Blockade of lactate transport exacerbates delayed neuronal damage in a rat model of cerebral ischemia. Brain Res. 895, 268272.

7. Lopez-Fabuel, I., Le Douce, J., Logan, A., James, A. M., Bonvento, G., Murphy, M. P., Almeida, A., and Bolanos, J. P. (2016) Complex I assembly into supercomplexes determines differential mitochondrial ROS production in neurons and astrocytes. Proc. Natl. Acad. Sci. USA 113, 1306313068.

8. Azarias, G., and Chatton, J. Y. (2011) Selective Ion Changes during Spontaneous Mitochondrial Transients in Intact Astrocytes. PLoS One 6, e28505.

9. Zerangue, N., and Kavanaugh, M. P. (1996) Flux coupling in a neuronal glutamate transporter. Nature 383, 634-637.

10. Rose, C. R., and Ransom, B. R. (1996) Mechanisms of $\mathrm{H}^{+}$and $\mathrm{Na}^{+}$changes induced by glutamate, kainate, and D-aspartate in rat hippocampal astrocytes. J. Neurosci. 16, 5393-5404.

11. Amato, A., Ballerini, L., and Attwell, D. (1994) Intracellular pH changes produced by glutamate uptake in rat hippocampal slices. J. Neurophysiol. 72, 1686-1696.

12. Mitchell, P. (1979) Keilin's respiratory chain concept and its chemiosmotic consequences. Science 206, 1148-1159.

13. Azarias, G., Perreten, H., Lengacher, S., Poburko, D., Demaurex, N., Magistretti, P. J., and Chatton, J.-Y. (2011) Glutamate transport decreases mitochondrial pH and modulates oxidative metabolism in astrocytes. J. Neurosci. 31, 3550-3559.

14. Coles, J. A., Orkand, R. K., Yamate, C. L., and Tsacopoulos, M. (1986) Free concentrations of Na, K, and $\mathrm{Cl}$ in the retina of the honeybee drone: stimulus-induced redistribution and homeostasis. Ann. N. Y. Acad. Sci 481, 303-317. 
15. Newman, E. A. (1986) High potassium conductance in astrocyte endfeet. Science 233, 453-454.

16. Olsen, M. (2012) Examining potassium channel function in astrocytes. Methods Mol Biol 814, 265281.

17. Kofuji, P., and Newman, E. A. (2004) Potassium buffering in the central nervous system. Neuroscience 129, 1045-1056.

18. Amzica, F. (2002) In vivo electrophysiological evidences for cortical neuron-glia interactions during slow $(<1 \mathrm{~Hz})$ and paroxysmal sleep oscillations. J Physiol Paris 96, 209-219.

19. Larsen, B. R., Assentoft, M., Cotrina, M. L., Hua, S. Z., Nedergaard, M., Kaila, K., Voipio, J., and MacAulay, N. (2014) Contributions of the $\mathrm{Na}^{+} / \mathrm{K}^{+}$-ATPase, NKCC1, and Kir4.1 to hippocampal $\mathrm{K}^{+}$ clearance and volume responses. Glia 62, 608-622.

20. Ruminot, I., Gutierrez, R., Pena-Munzenmayer, G., Anazco, C., Sotelo-Hitschfeld, T., Lerchundi, R., Niemeyer, M. I., Shull, G. E., and Barros, L. F. (2011) NBCe1 mediates the acute stimulation of astrocytic glycolysis by extracellular $\mathrm{K}^{+}$. J. Neurosci. 31, 14264-14271.

21. Brookes, N., and Turner, R. J. (1994) $\mathrm{K}^{+}$-induced alkalinization in mouse cerebral astrocytes mediated by reversal of electrogenic $\mathrm{Na}^{+}-\mathrm{HCO}^{-}$cotransport. Am. J. Physiol 267, C1633-1640.

22. Bittner, C. X., Valdebenito, R., Ruminot, I., Loaiza, A., Larenas, V., Sotelo-Hitschfeld, T., Moldenhauer, H., San Martin, A., Gutierrez, R., Zambrano, M., and Barros, L. F. (2011) Fast and reversible stimulation of astrocytic glycolysis by $\mathrm{K}^{+}$and a delayed and persistent effect of glutamate. J. Neurosci. 31, 4709-4713.

23. Lamy, C. M., and Chatton, J. Y. (2011) Optical probing of sodium dynamics in neurons and astrocytes. Neurolmage 58, 572-578.

24. Rimmele, T., and Chatton, J.-Y. (2014) A novel optical intracellular imaging approach for potassium dynamics in astrocytes. PLOS ONE in press.

25. Poburko, D., Santo-Domingo, J., and Demaurex, N. (2011) Dynamic regulation of the mitochondrial proton gradient during cytosolic calcium elevation. J. Biol. Chem. 286, 11672-11684.

26. Perreten Lambert, H., Zenger, M., Azarias, G., Chatton, J. Y., Magistretti, P. J., and Lengacher, S. (2014) Control of Mitochondrial pH by Uncoupling Protein 4 in Astrocytes Promotes Neuronal Survival. J. Biol. Chem. 289, 31014-31028. .

27. Bernardi, P. (1999) Mitochondrial transport of cations: channels, exchangers, and permeability transition. Physiol. Rev. 79, 1127-1155.

28. Chesler, M., and Kraig, R. P. (1987) Intracellular pH of astrocytes increases rapidly with cortical stimulation. Am. J. Physiol 253, R666-R670.

29. Deitmer, J. W., and Rose, C. R. (1996) pH regulation and proton signalling by glial cells. Prog. Neurobiol. 48, 73-103.

30. Schmitt, B. M., Berger, U. V., Douglas, R. M., Bevensee, M. O., Hediger, M. A., Haddad, G. G., and Boron, W. F. (2000) Na/HCO3 cotransporters in rat brain: expression in glia, neurons, and choroid plexus. J. Neurosci. 20, 6839-6848. 
31. Chesler, M. (2003) Regulation and modulation of pH in the brain. Physiol. Rev. 83, 1183-1221.

32. Heinemann, U., and Lux, H. D. (1977) Ceiling of stimulus induced rises in extracellular potassium concentration in the cerebral cortex of cat. Brain Res. 120, 231-249.

33. Brierley, G. P., Baysal, K., and Jung, D. W. (1994) Cation transport systems in mitochondria: $\mathrm{Na}^{+}$ and $\mathrm{K}^{+}$uniports and exchangers. Journal of Bioenergetics and Biomembranes 26, 519-526.

34. Rimmele, T., Rocher, A.-B., Wellbourne-Wood, J., and Chatton, J.-Y. (2017) Control of glutamate transport by extracellular potassium: basis for a negative feedback on synaptic transmission. Cereb. Cortex 27, 3272-3283.

35. Kahlert, S., Zundorf, G., and Reiser, G. (2008) Detection of de- and hyperpolarization of mitochondria of cultured astrocytes and neurons by the cationic fluorescent dye rhodamine 123. J Neurosci Methods 171, 87-92.

36. Sorg, O., and Magistretti, P. J. (1992) Vasoactive intestinal peptide and noradrenaline exert longterm control on glycogen levels in astrocytes: blockade by protein synthesis inhibition. J. Neurosci. $12,4923-4931$.

37. Chatton, J.-Y., Marquet, P., and Magistretti, P. J. (2000) A quantitative analysis of L-glutamateregulated $\mathrm{Na}^{+}$dynamics in mouse cortical astrocytes: implications for cellular bioenergetics. Eur. J. Neurosci. 12, 3843-3853.

38. Chatton, J.-Y., Idle, J. R., Vågb $\varnothing$, C. B., and Magistretti, P. J. (2001) Insights into the mechanisms of ifosfamide encephalopathy: drug metabolites have agonistic effects on a-amino-3-hydroxy- 5methyl-4-isoxazolepropionic acid (AMPA)/kainate receptors and induce cellular acidification in mouse cortical neurons. J. Pharmacol. Exp. Ther. 299, 1161-1168.

39. Duchen, M. R. (1992) Ca2+-dependent changes in the mitochondrial energetics in single dissociated mouse sensory neurons. Biochem. J. 283, 41-50.

40. Scaduto, R. C., Jr., and Grotyohann, L. W. (1999) Measurement of mitochondrial membrane potential using fluorescent rhodamine derivatives. Biophys. J. 76, 469-477. 